\title{
Outcome determinants for isocyanate induced occupational asthma among compensation claimants
}

Susan M Tarlo, Daniel Banks, Gary Liss, Irvin Broder

\begin{abstract}
Objectives-To compare the outcome of occupational asthma (OA) induced by isocyanates in Ontario (where a surveillance programme for exposed workers has been in place for over 15 years), with the outcome of $\mathrm{OA}$ induced by other work agents.
\end{abstract}

Methods-Compensated OA claims during the period 1984-88 in Ontario were retrospectively reviewed in a standardised way.

Results-136/235 compensated claims were attributed to isocyanates. Compared with other causes of $O A$, those attributed to isocyanates had a shorter latent period before onset $(5.9 v 7.9$ years, $P<0.05)$, shorter duration of symptoms before diagnosis (2.0 $v$ 3.0 years, $P<0.05)$, and less associated atopy $(43 \% v 58 \%, P<0.05)$. Outcome at a mean of 1.9 years after initial assessment was significantly better in those with $\mathrm{OA}$ induced by isocyanates; $73 \%$ cleared or improved $v 56 \%$ with other causes of $O A(P<0.05)$. Ten subjects with $O A$ induced by isocyanates stayed at the same work; none cleared and four had worsened at follow up. A better outcome in $O A$ induced by isocyanates was associated with early diagnosis $(P<0.05)$, and early removal from isocyanates after the onset of asthma.

Conclusions-The outcome in the group with $O A$ induced by isocyanates is similar to previous follow up studies. However, it is better than the outcome in our comparison group with $O A$ due to other causes, perhaps because of earlier diagnosis in the group with OA induced by isocyanates. This may be attributable to the medical surveillance of workers exposed to isocyanates in Ontario, either directly from the surveillance assessments, or indirectly by increasing awareness of the condition.

(Occup Environ Med 1997;54:756-761)

Keywords: isocyanates; occupational asthma; outcome

Isocyanates are widely used in many parts of the world, especially in the manufacture of polyurethane foam and in spray paints. They have been reported to be the commonest cause of occupational asthma (OA) in Quebec, ${ }^{1}$
Ontario, ${ }^{23}$ and Great Britain. ${ }^{4}$ In a recent review by us of Ontario Workers' Compensation Board (WCB) claims for OA, exposure to isocyanates was identified in $30 \%$ of claims submitted and in $58 \%$ of claims accepted for OA. $^{3}$

The outcome after removal from exposure has been relatively poor in $\mathrm{OA}$ induced by isocyanates. ${ }^{5-10}$ By contrast with the report by Chan Yeung $e t a l^{11}$ of clearing of asthma symptoms in $84 \%$ of red cedar workers with $\mathrm{OA}$ after removal from exposure, clearing of asthma symptoms in those with OA induced by isocyanates has been reported in $0 \%-28 \%$ of subjects, ${ }^{5-10}$ and $50 \%$ of subjects in one report. ${ }^{8}$ The report of Chan Yeung et al ${ }^{11}$ in cedar workers and our report ${ }^{3}$ in a large group of claims compensated for $\mathrm{OA}$ from various causes have shown an association between early removal from exposure after diagnosis and better outcome of OA.

Unlike previous reports, our review of Ontario compensation claims for $\mathrm{OA}^{3}$ allowed us to compare large groups of patients with $O A$ induced by isocyanates with those induced by other causes. That study identified a significantly better outcome for asthma induced by isocyanates than OA from other causes. We have therefore further characterised this population with OA induced by isocyanates to identify factors that may have accounted for this better outcome.

\section{Material and methods}

Files were reviewed of all claims for occupational asthma submitted to the Ontario Workers' Compensation Board (WCB) between mid-1984 and mid-1988 inclusive. From each file a standardised format was completed, from the most detailed assessments before and after the WCB decision. Information was abstracted as previously described ${ }^{3}$ - namely, demographic details, type and duration of work exposure, details of symptoms attributed to work, history of any previous asthma, medication, and results of investigations. Also abstracted were the diagnostic decision by WCB; and follow up results obtained one to two years later, including work status, symptoms, medication, and pulmonary function results.

Patients were classified according to the presence or absence of exposure to isocyanates, and additional review of the files was performed to determine the type of work exposure and the type of isocyanates used. Exposure to
Accepted 27 May 1997 
isocyanates was assessed from information in the WCB file: documentation in the physicians' letters, and, where available, results of Ontario Ministry of Labour workplace reports. When more than one type of isocyanate exposure was present it was generally not possible to assess which type was responsible for asthma. For purposes of classification we ascribed those cases to the isocyanate which was present in the work area and which appeared first in the following order; (a) toluene diisocyanate, $(b)$ diphenyl methane diisocyanate, $(c)$ hexamethylene diisocyanate, $(d)$ other types of isocyanate.

The decision by WCB was used to classify patients as (a) occupational asthma, (b) aggravation of asthma, (c) unrelated asthma, and (d) other decision. In Ontario, claims to the WCB for suspected $\mathrm{OA}$ are usually initiated by a physician, either the company physician, family doctor, medical specialist, emergency room physician. Physicians of the WCB specialising in this area then gather and review medical documentation and environmental exposure data as relevent. Often they will request an independent medical assessment from a respiratory or occupational physician with a major interest in OA. The WCB decision is then reached by an occupational physician at the Ontario WCB, based in large part on the independent specialist opinion when this was obtained. During the time of this study, three WCB physicians specialising in complex medical cases made these decisions. The initial decision is subject to appeal to the WCB and if the appeal is rejected, a further appeal can be made through the Workers Compensation Appeal Tribunal, consisting of a non-medical panel. Thus the final WCB decision could be reached at any of these stages but usually reflected the diagnosis of the most specialised non-WCB physician. ${ }^{3}$

A WCB decision of OA induced by isocyanates was generally reached in claims with new onset of clinical asthma while working with exposure to isocyanates, as well as objective documentation of asthma by demonstration of reversible airflow limitation on spirometry before and after bronchodilator, or by notable hyperresponsiveness to histamine or methacholine challenge. A diagnosis of $O A$ induced by isocyanates was considered to be objectively supported by positive findings from results of one or more of the following tests: serial peak flow recordings at work and off work, or serial methacholine or histamine challenges, or specific challenge with a workplace agent. The diagnosis "aggravation of asthma" by isocyanate was generally applied to asthma which occurred at work, with a history of preceding asthma apparently transiently worsened by accidental irritant exposure concentrations of isocyanates.

Follow up assessments were performed for disability decisions in subjects whose claims were accepted for occupational asthma and aggravation of asthma if respiratory impairment related to work was present at the initial assessment. The follow up assessment for disability rating was generally performed one to two years after the initial WCB decision, either by one of the three WCB physicians or a respiratory specialist selected by the WCB. This included a medical history, medication requirements, and pulmonary function testing. As with the initial assessment, there was no standardised format for the follow up assessment. Therefore, the outcome of asthma compared with the initial assessment was recorded for the purpose of this study as a global rating of asthma at that time, based on the assessing physician's letter. This was categorised relative to the initial data as cleared, improved, unchanged, or worsened asthma. The outcome was transcribed from the chart by the research assistant without knowledge of the intent to compare outcome of $\mathrm{OA}$ induced by isocyanates with that from other causes of $\mathrm{OA}$. When the results of spirometry, methacholine, or histamine challenge results were available in the file, these were also included in the study data for later comparison with the global assessment rating.

Information was obtained from the Ontario Ministry of Labour as to whether or not the workplace of each patient with $\mathrm{OA}$ induced by isocyanates was recorded to be compliant with the isocyanate medical surveillance programme in the year during which OA had been diagnosed. Such information is recorded at the Ministry of Labour if a worksite visit has been made. This visit often results from a WCB or physician request in conjunction with a WCB claim, but could also occur at the request of workers or the company, or could be initiated by the Ministry of Labour when a company has been identified as using isocyanates. The duration of symptoms before diagnosis and the outcome of OA induced by isocyanates was compared for patients with and without known surveillance in the workplace.

\section{STATISTICAL ANALYSIS}

Statistical analysis was performed with the SAS package with GLM for analysis of variance, T TEST for Student's $t$ tests, and FREQ for $\chi^{2}$ analyses. Values are mean (SD). As information available in the files was not complete for all patients, missing data were excluded from calculations of percentages and from statistical analyses.

\section{Results}

TOTAL GROUP OF WCB CLAIMS FOR OA

The characteristics of the total population from 609 WCB claim files have previously been described. ${ }^{3}$ The number of claims for the full years 1985-7 were 148, 148, and 153 and were 75 and 78 for the partial years 1984 and 1988 . A decision of occupational asthma (OA) was reached in $39 \%$ of subjects by the WCB. A similar proportion was given a decision by the WCB of aggravation of asthma.

Incidence of $O A$ induced by isccyanates compared with other $O A$

Of the 235 claims with a WCB decision of OA, $58 \%$ (136 accepted claims) were attributed to isocyanates on the basis of exposure in the workplace as documented in the WCB file. 
Table 1 Comparison of patients with isocyanate $O A$ and other $O A$

\begin{tabular}{llll}
\hline & Isocyanate OA & Other OA & P Value \\
\hline Number & 136 & 99 & \\
Age (mean (SD)) & $38(12)$ & $42(13)$ & $\mathrm{NS}$ \\
\% Male & 66 & 74 & $\mathrm{NS}$ \\
Current or ex-smokers (\%) & 70 & 65 & $\mathrm{NS}$ \\
Pack-years of smoking (mean (SD)) & $15(17)$ & $13(12)$ & $\mathrm{NS}$ \\
Nasal symptoms (\%) (number with information) & $74(91)$ & $87(71)$ & $<0.05$ \\
Exposure (y) before onset of OA (mean (SD)) & $5.9(7.1)$ & $7.9(8.1)$ & $<0.05$ \\
Exposure (y) after onset of OA (mean (SD)) & $2.0(3)$ & $3.0(5)$ & $<0.01$ \\
Years of symptoms before initial WCB assessment & & & \\
$\quad$ (mean (SD)) & $2.4(2.9)$ & $4.0(5.8)$ & $<0.01$ \\
FVC (\% predicted): & 100 & 94 & $\mathrm{NS}$ \\
$\quad$ FEV & 81 & 76 & $\mathrm{NS}$ \\
FEF & 86 & 76 & $\mathrm{NS}$ \\
$\quad$ FEF & & & \\
Methacholine PC $_{20}:$ & $5.2(11)$ & $4.0(10)$ & $\mathrm{NS}$ \\
$\quad$ Mean (SD, mg/ml) & 45 & 38 & \\
$\quad$ Working (n) & & & \\
Methacholine PC $_{20}:$ & $11.2(15)$ & $9.7(15)$ & $\mathrm{NS}$ \\
$\quad$ Mean (SD, mg/ml) & 75 & 57 & \\
$\quad$ Off work (n) & $3.8(6.9)$ & $4.5(12.8)$ & $\mathrm{NS}$ \\
PC $_{20}$ at work (mean (SD)) & $14.8(21)$ & $12.2(17.7)$ & $\mathrm{NS}$ \\
PC $_{20}$ off work (mean (SD)) & 28 & 24 & \\
Those with both tests (n) & & & \\
\hline
\end{tabular}

$\overline{\mathrm{FVC}}=$ forced vital capacity $\mathrm{FEV}_{1}=$ forced expiratory volume in one second $\mathrm{FEF}_{50}=$ forced expiratory flow at $50 \% \mathrm{VC}$.

Most patient characteristics did not differ from those with other OA derived from the total group previously described (table 1$).^{3}$ Sixty six per cent were men and the mean age was 38 (12) years. Seventy per cent were current or ex-smokers with a mean of 15 (17) pack years. The presence of work related nasal symptoms was noted in $74 \%$ of the 91 patients with information available, a significantly lower proportion than in other OA $(\mathrm{P}<0.05)$. Atopy was found in $43 \%$ of the 80 patients tested (at least one positive skin test to a common aeroallergen), a significantly lower proportion than those with other OA 58\% ( $\mathrm{P}<0.05)$. Onset of symptoms occurred after a shorter latency period for OA induced by isocyanates than for other OA (mean 5.9 (7.1) $v 7.9$ (8.1) years, $P<0.05)$, peaking in the first year of exposure (figure). The mean duration of exposure after the onset of symptoms (table 1) was shorter (2.0 (3) $v 3.0$ (5) years, $\mathrm{P}<0.01$ ) at the time of the initial WCB assessment.

A history of symptom improvement in the OA induced by isocyanates group on weekends off work was present in $71 \%$ and on holidays in $89 \%$. A history of immediate asthmatic responses at work was described by $12 \%$, isolated late responses by $59 \%$, and dual responses by $29 \%$. At the main assessment, $78 \%$ were receiving inhaled bronchodilators, $58 \%$ inhaled steroids, $50 \%$ theophylline products, and

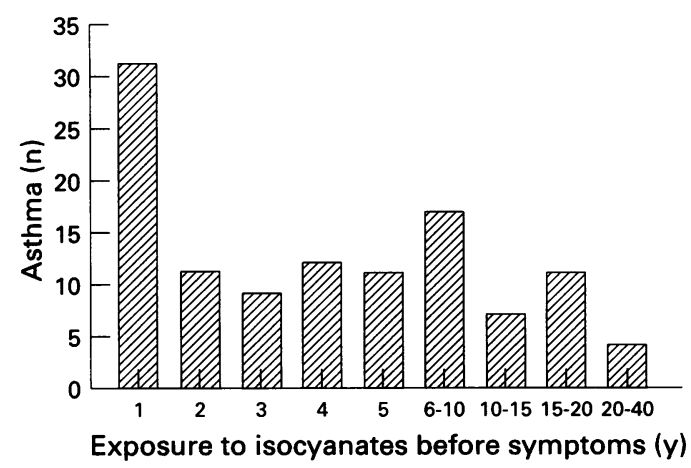

Years of exposure to isocyanates before the onset of symptoms of $O A$.
$10 \%$ oral steroids (mean dose $5.8(2) \mathrm{mg} /$ day of prednisone). These variables did not significantly differ from the patients with other OA.

The implicated main isocyanate exposure was to toluene diisocyanate in $43 \%$, diphenyl methane diisocyanate in $35 \%$, hexamethylene diisocyanate in $5 \%$, and other isocyanates or unspecified isocyanates in $17 \%$. The exposure to isocyanates was in the use of foam (52\%), spray painting (29\%), foam making (13\%), and other exposures $(7 \%)$.

Investigations showing an objective relation of asthma to the workplace were only available in $43 \%$ of accepted claims for OA induced by isocyanates. At the initial WCB assessment, only $20 \%$ were still at the same work, likely limiting further workplace pulmonary function investigations. Twenty two per cent already had clearing of symptoms by this assessment whereas $75 \%$ described continued limitation of activities by asthma symptoms. A methacholine or histamine challenge had been performed while working with isocyanates in 46 subjects (mean (SD) $\mathrm{PC}_{20} 5.2$ (11) $\mathrm{mg} / \mathrm{ml}$ ) and off work in 75 (mean PC $_{20} 11.2$ (15) $\mathrm{mg} / \mathrm{ml}$ ). Among the 28 subjects who performed methacholine or histamine challenges both when working and away from work, the ratios were similar in the two groups (table 1). Peak flow monitoring at work and off work had been adequately completed in 50 subjects and was supportive of the diagnosis in 30 subjects. Specific isocyanate challenges were performed in 25 subjects and were positive in 21 ( $84 \%)$. The results were similar for those with OA due to other causes. Among accepted claims for OA induced by isocyanates, there were no significant differences between the groups for demographic variables, symptoms, medication, and spirometry results between those who did and did not have objective confirmation of $\mathrm{OA}$ except for the methacholine challenge results at work (mean (SD) $\mathrm{PC}_{20} 2.9$ (4.3) $\mathrm{mg} / \mathrm{ml}$ in 31 confirmed cases $v 10.1$ (17.4) $\mathrm{mg} / \mathrm{ml}$ in 15 unconfirmed but accepted claims, $\mathrm{P}<0.05)$.

Outcome of $O A$ induced by isocyanates compared with other $O A$ in the same WCB claims population

The subjects with OA induced by isocyanates who underwent a follow up assessment had a better outcome than those with other OA accepted by the Ontario WCB in the same period (table 2). Follow up was obtained in 114 of $136(84 \%)$ of those with OA induced by isocyanates, at a mean of 1.8 years after the initial assessment and in 86 of $99(87 \%)$ with other OA after a mean of 2.1 years. At follow up assessment, asthma had cleared in $20 \%$ of OA induced by isocyanates $v 17 \%$ of OA not induced by isocyanates, was improved in $53 \% v$ $39 \%$, unchanged in $14 \% v 28 \%$, and worse in $13 \% v 15 \%$. Those with OA induced by isocyanates were significantly more likely to clear or improve than those with other causes of OA $(P<0.05)$, despite the shorter follow up in the OA induced by isocyanates group. The objective pulmonary function variables were also significantly better in $\mathrm{OA}$ induced by isocyanates than other $\mathrm{OA}$ at follow up (table 2). 
Table 2 Follow up of isocyanate $O A$ and other $O A$

\begin{tabular}{|c|c|c|c|}
\hline & Isocyanate $O A$ & Other $O A$ & $P$ value \\
\hline Number & 114 & 86 & \\
\hline Years since initial assessment (mean (SD)) & $1.8(1.6)$ & $2.1(1.5)$ & NS \\
\hline Removed from exposure (\%) & 89 & 81 & NS \\
\hline \multicolumn{4}{|l|}{ Symptoms (\%): } \\
\hline Cleared & 20 & 17 & \\
\hline Improved & 53 & 39 & $<0.05$ \\
\hline Years since clearing (mean (SD)) & $3.0(3.1)$ & $2.6(2)$ & NS \\
\hline Years since improving (mean (SD)) & $3.4(3)$ & $4.4(6.7)$ & $<0.001$ \\
\hline \multicolumn{4}{|l|}{ Follow up visit (mean (SD)): } \\
\hline $\mathrm{FEV}_{1}$ (\% predicted) & $102(19)$ & $90.2(26)$ & $<0.01$ \\
\hline FVC & 109 (16) & $102(21)$ & $<0.01$ \\
\hline $\mathrm{FEF}_{50}$ & $82(33)$ & $65 \quad(35)$ & NS \\
\hline $\mathrm{FEF}_{75}$ & 83 (41) & $74 \quad(38)$ & NS \\
\hline \multicolumn{4}{|l|}{ Methacholine $\mathrm{PC}_{20}$ : } \\
\hline Mean (SD, $\mathrm{mg} / \mathrm{ml})$ & $10.8(12.9)$ & $7.5(6.3)$ & $<0.001$ \\
\hline Subjects (n) & 30 & 27 & \\
\hline
\end{tabular}

Footnotes as for table 1 . challenge data. Also, outcome was not related to the spirometric variables at the initial visit (table 3). The methacholine or histamine $\mathrm{PC}_{20}$ at the initial visit was significantly better in those who were categorised as having clearing of asthma at follow up, but may be explained by the proportion of subjects $(22 \%$ of the total patients) who already had clearing of asthma symptoms by the initial assessment. There was no difference in outcome among the patients with objectively confirmed OA compared with the group diagnosed without serial pulmonary function tests or isocyanate challenges in the workplace.

Records obtained from the Ontario Ministry of Labour indicated that 71 patients with OA induced by isocyanates $(52 \%)$ worked in plants that were compliant with medical surveillance measures for isocyanate during the year of their diagnosis. These patients had a significantly earlier diagnosis (at a mean of 1.7 (2.4) years after the onset of symptoms) compared with those from plants without known compliance with the suveillance programme (diagnosed at a mean 2.7 (3.1) years after the onset of symptoms, $\mathrm{P}<0.05$ ).

Outcome for the 59 patients whose workplaces had surveillance measures in place was not significantly different from those without surveillance: $22 \% \quad v \quad 18 \%$ had clearing of asthma at follow up, whereas $51 \% v 55 \%$ had improved. However, worsening of asthma at follow up was recorded in $8 \%$ of those from plants with surveillance versus $18 \%$ of those without known surveillance.

\section{Discussion}

This study has an advantage over most previous studies of outcome of OA induced by isocyanates due to the presence of an internal comparison group of other Ontario WCB accepted claims for $\mathrm{OA}$, and due to the relatively large numbers of patients relative to other studies. The number of workers on which previous studies have been based ranged from 12 to $50 .^{5-10}$ The mean duration of exposure to isocyanates after the onset of symptoms of asthma in our study, 2.0 years (table 1), asthmatic response (early, late, or dual response) by history or from peak flow or specific

Table 3 Objective outcome variables for isocyanate $O A$ in 114 patients

\begin{tabular}{|c|c|c|c|c|c|c|c|c|c|}
\hline & \multicolumn{2}{|c|}{ Cleared } & \multicolumn{2}{|c|}{ Milder } & \multicolumn{2}{|c|}{ Unchanged } & \multicolumn{2}{|c|}{ Worse } & P value \\
\hline At follow up (n) & \multicolumn{2}{|l|}{23} & \multicolumn{2}{|l|}{60} & \multicolumn{2}{|c|}{16} & \multicolumn{2}{|l|}{15} & \\
\hline Years of symptoms before leaving exposure & \multicolumn{2}{|c|}{$1.2(1.8)$} & \multirow{2}{*}{\multicolumn{2}{|c|}{$\begin{array}{l}2.4(3.0) \\
2.7(2.8)\end{array}$}} & \multicolumn{2}{|c|}{$1.1(1.4)$} & \multicolumn{2}{|c|}{$4.4(3.9)$} & $<0.01$ \\
\hline Years of symptoms before main assessment & \multicolumn{2}{|c|}{$2.0(2.8)$} & & & \multicolumn{2}{|c|}{$1.4(1.5)$} & \multicolumn{2}{|c|}{$4.0(3.8)$} & $<0.05$ \\
\hline Years of exposure before onset of symptoms & \multicolumn{2}{|c|}{2.4} & & \multicolumn{2}{|c|}{11.3} & \multicolumn{2}{|c|}{6.7} & $<0.005$ \\
\hline \multicolumn{8}{|l|}{ Initial methacholine $\mathrm{PC}_{20}$ : } & & \\
\hline At work (mean (SD, mg/ml) & 24 & (30) & \multirow{2}{*}{\multicolumn{2}{|c|}{$\begin{array}{l}3.0(4) \\
24\end{array}$}} & \multirow{2}{*}{\multicolumn{2}{|c|}{$\begin{array}{l}0.6(0.6) \\
6\end{array}$}} & \multirow{2}{*}{\multicolumn{2}{|c|}{$\begin{array}{l}2.6(5.4) \\
8\end{array}$}} & 0.001 \\
\hline Assessed (n) & 4 & & & & & & & & \\
\hline \multicolumn{10}{|l|}{ Follow up methacholine $\mathrm{PC}_{20}$ : } \\
\hline Mean $(\mathrm{SD}, \mathrm{mg} / \mathrm{ml})$ & 28 & $(24)$ & \multicolumn{2}{|c|}{$9.3(9.1)$} & \multicolumn{2}{|c|}{$8.7(6.7)$} & \multicolumn{2}{|c|}{$2.3(2.2)$} & $<0.05$ \\
\hline Assessed (n) & 4 & & 19 & & 3 & & 4 & & \\
\hline \multicolumn{10}{|l|}{ Initial spirometry (mean (SD)): } \\
\hline $\mathrm{FEV}_{1}(\%$ predicted $)$ & 105 & (26) & 96 & (24) & 107 & (14) & 105 & $(25)$ & NS \\
\hline FVC & 108 & (24) & 102 & (22) & 110 & (14) & 107 & (12) & NS \\
\hline $\mathrm{FEF}_{50}$ & 104 & (53) & 75 & (36) & 90 & (24) & 67 & (25) & NS \\
\hline $\mathrm{FEF}_{75}$ & 85 & (54) & 68 & (47) & 77 & (19) & 104 & $(106)$ & NS \\
\hline \multirow{2}{*}{\multicolumn{10}{|c|}{ Follow up spirometry (mean (SD)): }} \\
\hline & & & & & & & & & \\
\hline $\mathrm{FEV}_{1}$ (\% predicted) & 113 & (16) & 104 & (17) & 101 & (17) & 80 & (18) & 0.001 \\
\hline FVC & 117 & (13) & 108 & (15) & 107 & (14) & 97 & (18) & $<0.02$ \\
\hline $\mathrm{FEF}_{50}$ & 96 & (32) & 82 & (31) & 91 & (27) & 44 & (24) & NS \\
\hline $\mathrm{FEF}_{75}$ & 97 & (46) & 76 & (38) & 93 & (32) & 31 & (16) & NS \\
\hline With information (n) & 17 & & 44 & & 12 & & 10 & & \\
\hline
\end{tabular}

Footnotes as for table 1. 
compares with exposure means of 2.7 to 3.8 years in the other reports of outcome of OA induced by isocyanates in which symptoms cleared in $18 \%-28 \%$ of subjects ( $v 20 \%$ of those followed up in our study or $30 \%$ including those clear of asthma by the first assessment). In the study reported by Rosenberg et $a l^{\beta}$ in which asthmatic symptoms cleared in $50 \%$ of subjects with OA induced by isocyanates, the mean exposure after the onset of asthma symptoms was 1.2 years. However, criteria used for categorising outcome varied from study to study and therefore should be compared with caution.

The diagnosis of OA was not objectively confirmed in all the WCB claims accepted for $O A$ and some may have had coincidental asthma, perhaps accounting for a higher proportion of atopic asthmatic patients with this diagnosis compared with previous reports. ${ }^{5-9}$ Nevertheless, the outcome was not different in those with objective confirmation of the work relation compared with those without objective confirmation (data not shown). Also, those with coincidental asthma would not be expected to have an improvement in asthma after leaving work, and would not likely account for the overall better outcome in this study compared with several other reports.

The outcome is also better than in the group of other OA claims accepted by the Ontario WCB in the same period as this study, perhaps related to the shorter duration of symptoms before diagnosis and removal from exposure in the $\mathrm{OA}$ induced by isocyanates group (tables 1 and 3 ). The better outcome compared with other OA may also relate to the shorter latency of OA induced by isocyanates compared with other causes. A shorter latency of OA due to isocyanates compared with OA from high molecular weight allergens has been previously reported by Malo et al. ${ }^{12}$ Chan Yeung et al have also reported that early development of OA with red cedar was associated with a better prognosis. $^{11}$

The shorter exposure time in our group with $\mathrm{OA}$ induced by isocyanates compared with other OA may reflect the value of the medical surveillance programme for isocyanate present in Ontario. This programme demands ${ }^{13}$ that workplaces using these substances offer workers medical surveillance involving preplacement medical questionnaires including questions to detect asthmatic symptoms, as well as physical examination and spirometry. The questionnaire must be repeated at least every six months with spirometry if indicated at that time, or spirometry at least every two years. A $15 \%$ fall in forced expiratory volume in one second $\left(\mathrm{FEV}_{1}\right)$ or vital capacity $(\mathrm{VC})$ requires a referral for further medical assessment. Although specific information was not available at the Ontario Ministry of Labour for all plants that used isocyanates, about half of the cases of $\mathrm{OA}$ induced by isocyanates came from plants known to comply with this programme, and these accounted for the earlier mean diagnosis of $\mathrm{OA}$ induced by isocyanates compared with other causes of OA. It is not known whether the earlier diagnosis is due to the increased aware- ness by workers and healthcare providers of $O A$ induced by isocyanates which is promoted by the existence of the programme or due to the questionnaire or spirometry. To our knowledge, this is the first study which suggests that a routine surveillance programme may have value in early detection of OA induced by isocyanates.

Continued exposure in the workplace, another variable which has been previously associated with a worse outcome, ${ }^{14}{ }^{15}$ was also associated with a worse outcome within our group of subjects with OA induced by isocyanates (tables 2 and 3). However, the timing of the acute asthmatic response (early, late, or dual) was not a factor, unlike a report of subjects with red cedar OA; $;^{11}$ nor was the degree of initial airflow limitation. ${ }^{311}$ Also, we did not find a significant difference in outcome related to the type of isocyanate used or the type of occupational exposure.

Legislated allowable exposure limits in Ontario since 1983 for isocyanates have been a time weighted average not exceeding 0.005 ppm and a short term exposure limit of 0.02 ppm. ${ }^{13}$ Despite this legislation, isocyanates have remained the most common sensitiser in compensated claims for $\mathrm{OA}$ in Ontario. A recent assessment by us has suggested that the risk of OA induced by isocyanates is increased with higher measured environmental concentrations of isocyanates. ${ }^{16}$ Further studies are needed to determine whether cases of $\mathrm{OA}$ arise from accidental short term breaches of allowable limits or whether longer term high exposures are occurring above recommended levels. It has been suggested that good engineering controls and low isocyanate concentrations can considerably reduce sensitisation. ${ }^{15}$ The high proportion of OA due to isocyanates in this study emphasises the need for workers to follow appropriate safety procedures in the workplace, especially when exposure levels are likely to be increased (as in cleaning or maintaining equipment).

Our findings also emphasise the need for an early accurate diagnosis of OA induced by isocyanates with removal from exposure as soon as possible. Such an early diagnosis might be enhanced by medical surveillance programmes such as those which exist in Ontario. However, the value of such programmes in achieving this goal requires direct objective evaluation as has been suggested in a recent consensus statement on occupational asthma. ${ }^{17}$

We thank Mary Harpur and Justina Greene for data gathering and processing, Ms Laurel O'Connor for typing assistance, and Dr C Smith, Dr P Carr, and Dr R Thakur of the Ontario Workers' Compensation Board for their cooperation in this study. The study was supported by the Ontario Workers' Compensation Board.

1 Malo JL. Compensation for occupational asthma in Quebec. In: Merchant JA, ed. Workshop on environmental and In: Merchant JA, ed. Workshop on envirom

2 Tarlo SM, Broder I. Outcome of assessment for occupational asthma. Chest 1991;100:329-35.

3 Tarlo SM, Liss G, Corey P, Broder I. A workers' compensation claim population for occupational asthma: comparison tion claim population for occupational
of subgroups. Chest 1995;107:634-41.

4 Meredith SK, Taylor VM, McDonald JC. Occupational respiratory disease in the United Kingdom: a report to the British Thoracic Society and the Society of Occupational Medicine by the SWORD project group. Br F Ind Med 1989;48:292-8. 
5 Paggiaro PL, Loi AM, Rossi O, Ferrante B, Pardi F, Roselli MG, Baschierri L. Follow up study of patients with respiratory disease due to toluene diisocyanate (TDI). Clin respiratory disease due

6 Mapp CE, Corona PC, DeMarzo N, Fabbri L. Persistent asthma due to isocyanates. Am Rev Respir Dis 1988;137: 1326-9.

7 Losewicz S, Assoufi BK, Hawkins R, Newman-Taylor AJ. Outcome of asthma induced by isocyanates. $B r F$ Dis Chest 1987;81:14-22.

8 Rosenberg N, Garnier R, Rousselin X, Mertz R, Gervais P. Clinical and socio-professional fate of isocyanate-induced asthma. Clin Allergy 1987;17:55-61.

9 Pisato G, Baruffini A, Zedda S. Toluene diisocyanate induced asthma: outcome according to persistence or cessation of exposure. Br F Ind Med 1993;50:60-4.

10 Paggiaro PL, Vagaggini B, Dente FL, Bacci E, Bancalari L, Carrara $\mathrm{M}$, et al. Bronchial hyperresponsiveness and toluene diisocyanate. Long term change in sensitized asthtoluene diisocyanate. Long term change
matic subjects. Chest 1993;103:1123-8.

11 Chan-Yeung M, MacLean l, Paggiaro PL. Follow up study of 232 patients with occupational asthma caused by western red cedar (Thuja plicata). $\mathcal{f}$ Allergy Clin Immunol 1987;79:792-6.
12 Malo JL, Ghezzo H, D'Aquino C, L'Archevêque J, Cartier A, Chan-Yeung $M$. Natural history of occupational asthma: relevance of type of agent and other factors in the rate of relevance of type of agent and other factors in the rate of
development of symptoms in affected subjects. $\mathcal{F}$ Allergy Clin Immunol 1992;90:937-44.

13 Ontario Ministry of Labour. Regulation respecting isocyanates made under the occupational health and safety act, 1980. Toronto, Ontario: Revised Statutes of Ontario, 1983. (Chapter 321. Ontario Regulation 455, 83.)

14 Cote J, Kennedy S, Chan-Yeung M. Outcome of patients with cedar asthma with and without continuing exposure. Am Rev Respir Dis 1990;141:373-6.

15 Bernstein DI, Korbee L, Stauder T, et al. The low prevalence of occupational asthma and antibodydependent sensitization to diphenylmethane diisocyanate in a plant engineered for minimal exposure to diisocyanates. F Allergy Clin Immunol 1993;92:387-96.

16 Tarlo SM, Liss GM, Dias C, Banks DE. Assessment of the relationship between isocyanate exposure levels and occupational asthma. Am f Ind Med 1997 (in press).

17 ACCP consensus statement: assessment of asthma in the workplace. Chest 1995;108:1084-117. 